\title{
Entre práticas [historiográficas e de desenho]: um movimento metodológico de pesquisa ${ }^{1}$
}

\section{Between historiographical and drawing's practices: a methodological movement of research}

\author{
Rosilene Beatriz Machado ${ }^{2}$ \\ Cláudia Regina Flores ${ }^{3}$
}

\begin{abstract}
Resumo
Este artigo tem por objetivo apresentar os caminhos teórico-metodológicos percorridos em uma pesquisa atual, que toma como unidade de análise práticas sociais [de desenhar]. Assim, busca-se discutir as ferramentas utilizadas para a escrita de uma história (arqueogenealógica) do desenho; uma história que não se opera sob um viés epistemológico, mas discursivo. Ainda, e desse modo, para uma prática historiográfica que não se limita estritamente a uma história da ciência ou uma história da educação, mas que atravessa distintos campos de saber, desenhando matemática[s] nas relações possíveis entre práticas de desenhar e práticas matemáticas sem, no entanto, limitar-se a elas.
\end{abstract}

Palavras-chave: história, desenho, práticas sociais

\begin{abstract}
This article aims to present the theoretical and methodological paths that have been taken in a current research that takes as a unit of analysis social practices [of drawing]. Thus, it discuss the tools used for the writing of a history of drawing that does not operate under an epistemological bias, but discursive. Yet, and thus, for a historiographical practice that limits are not strictly a history of science or history of education, but through various fields of knowledge, drawing math[s] on the possible relationships between practices of drawing and mathematical practices without, however, be limited to them.
\end{abstract}

Keywords: history, drawing, social practices

\footnotetext{
${ }^{1}$ Uma versão preliminar e parcial do trabalho foi apresentada no VI Seminário Internacional de Pesquisa em Educação Matemática (SIPEM), realizado entre 15 e 19 de novembro em Pirenópolis, Goiás, Brasil.

2 Doutoranda do Programa de Pós-Graduação em Educação Científica e Tecnológica (PPGECT), da Universidade Federal de Santa Catarina (UFSC). Professora do Departamento de Metodologia de Ensino, do Centro de Ciências da Educação, da Universidade Federal de Santa Catarina (MEN/CED/UFSC). Email: rosilene.machado@ufsc.br

${ }^{3}$ Professora do Programa de Pós-Graduação em Educação Científica e Tecnológica (PPGECT), da Universidade Federal de Santa Catarina (UFSC). Professora do Departamento de Metodologia de Ensino, do Centro de Ciências da Educação, da Universidade Federal de Santa Catarina (MEN/CED/UFSC). Coordenadora do Grupo de Estudos Contemporâneos e Educação Matemática (GECEM). Email: claudia.flores@ufsc.br
}

Zetetiké, Campinas, SP, v.24, n.2, maio/ago.2016, p.237-248 
http://periodicos.sbu.unicamp.br/ojs/index.php/zetetike

\section{Preambulando}

Nossa trajetória pelos territórios do desenho já vem de algum tempo. Mais propriamente, desde o enveredamento pelos estudos resultantes na dissertação de mestrado intitulada Entre vida e morte: cenas de um ensino de desenho (Machado, 2012). Percorrer esta trajetória implica, a cada vez e sempre, encontrar novos caminhos e possibilidades teórico-metodológicas. Isto porque o objeto é complexo, caótico, fluido, mas também porque essa trajetória dá-se sob territórios movediços de um grupo de pesquisa ${ }^{4}$ em que tanto pesquisa quanto história são concebidas como formas em movimentos, narrativas subjetivas, panoramas provisórios... Daí que, nesse percurso, temos permitido que teias teóricometodológicas emaranhem-nos, ativem potencialidades outras, iluminem pontos outrora obscuros... Apresentemos, então, neste texto, como se dá nossa movimentação e andanças atuais por tais caminhos...

\section{Situando}

Pois bem. Inicialmente cumpre dizer que temos tratado de história. Mas não unicamente de história (da matemática, do desenho, da ciência); tampouco de história da educação (matemática, do desenho, etc.). Procuramos, isso sim, atravessar esses campos de saber disciplinarizados e nos movimentar transversalmente entre eles. Se outrora nos debruçamos sobre a história de uma disciplina escolar específica no Brasil ${ }^{5}$, percebendo aí uma rede complexa (e contingencial) de elementos que sustentaram sua vida e morte, intentamos agora questionar que condições de possibilidade fizeram com que esse saber se disciplinarizasse. Com Foucault (2013) temos então perguntado: "como se puderam formar domínios de saber a partir de práticas sociais?" (p. 17). Isto para tentar mostrar "como práticas sociais podem chegar a engendrar domínios de saber que não somente fazem aparecer novos objetos, novos conceitos, novas técnicas, mas também fazem nascer formas totalmente novas de sujeitos e sujeitos de conhecimento" (p. 18).

O que nos afasta, ressalte-se, de uma compreensão que considera os conteúdos que compõem as disciplinas escolares transposições didáticas de conhecimentos científicos, tal como requer Chevallard (2009); e, também, daquela que concebe as disciplinas escolares como criações espontâneas da escola, pela escola e para a escola, como argumenta André Chervel (1990). O que temos considerado produtivo é entender, pois, as disciplinas escolares como resultantes de processos de escolarização disciplinarizadores de práticas socioculturais não escolares. Processos, por sua vez, que elegem certas práticas encenadas em contextos socialmente valorizados de atividade humana, extraindo de tais performances conteúdos considerados privilegiados e reencenando-as de um modo tipicamente escolar (isto é, fazendo

\footnotetext{
${ }^{4}$ Grupo de Estudos Contemporâneos e Educação Matemática (GECEM), sediado na Universidade Federal de Santa Catarina, coordenado pela Profa. Dra. Cláudia Regina Flores.

${ }^{5}$ Referente à dissertação de mestrado supracitada.
}

Zetetiké, Campinas, SP, v.24, n.2, maio/ago.2016, p.237-248 
a elas referência exclusivamente por meio de encenações verbais e/ou imagéticas da linguagem) (Miguel, 2014, p. 24, tradução nossa).

Sob este viés, operamos, portanto, um deslocamento de análise problematizando: como práticas sociais de desenhar teriam adquirido o estatuto de conteúdo escolar? ${ }^{6} \mathrm{O}$ que implica pressupor (não para provar, mas, tomando tal suposição, para explorar suas potencialidades) que investigar formas de vida não escolares de práticas de desenhar pode melhor esclarecer as características da forma de vida escolar dessas mesmas práticas; afinal, práticas de disciplinarização cultural (como as escolares) só são possíveis a partir de práticas de produção cultural (Miguel, 2010).

\section{Territorializando}

Para atacar esta problematização atual, entendemos que, estando as práticas de desenhar situadas historicamente (não nos possibilitando experienciá-las), elas só podem ser conhecidas graças aos discursos/elementos discursivos delas constitutivos e por elas constituídos mutuamente (Foucault, 2013, p. 143). E aí, por discurso é preciso tratar-se não de "conjuntos de signos (elementos significantes que remetem a conteúdos ou representações), mas de práticas que formam sistematicamente os objetos de que falam" (2009, p. 55). O que significa "interrogar a linguagem não na direção a que ela remete, mas na dimensão que a produz" (p. 126). Mais ainda, considerar que não possa haver realidade pré-discursiva; que não possa haver realidade antes ou fora do discurso que por esse seja representada. O discurso não assume, pois, um papel mediador, mas constitutivo da realidade.

Dito isso, sob essa perspectiva, práticas sociais (ou não discursivas), práticas culturais e práticas discursivas só podem ser entendidas em simbiose. As práticas discursivas são dadas sempre no interior de práticas sociais que, por sua vez, estão sempre investidas de discursividade. Em outras palavras,

cada instituição ou atividade social gera e requer seu próprio universo distinto de significados e práticas - sua própria cultura. ... Todas as práticas sociais, na medida em que sejam relevantes para $o$ significado ou requeiram significado para funcionarem, têm uma dimensão cultural. (Hall, 1997, p. 28)

Não se quer argumentar com isso que tudo seja cultural ou que tudo seja discursivo, mas que as práticas sociais relacionam-se e dependem do significado; que a cultura é, assim, uma das condições constitutivas de existência dessas práticas e que, portanto, "toda prática social tem uma dimensão cultural. Não que não haja nada além do discurso, mas que toda prática social tem o seu caráter discursivo" (p.28).

\footnotetext{
${ }^{6}$ Referente ao estudo em nível de doutoramento iniciado em 2012, realizado por Rosilene Beatriz Machado, no Programa de Pós-Graduação em Educação Científica e Tecnológica da Universidade Federal de Santa Catarina, sob orientação da Profa. Dra. Cláudia Regina Flores.
} 
http://periodicos.sbu.unicamp.br/ojs/index.php/zetetike

Assim sendo, se, como afirma Deleuze (2005, p.82), "segundo Foucault, tudo é prática", situar-se no âmbito dos discursos consiste, com efeito, em operar no território das práticas. Entretanto, considerar o próprio discurso como prática não significa entender aí a competência e a atividade de um sujeito, "e sim a existência objetiva e material de certas regras às quais o sujeito tem que obedecer quando participa do discurso" (Lecourt, 2008, p. 51); "um conjunto de regras anônimas, históricas, sempre determinadas no tempo e no espaço" (Foucault, 2009, p. 133). O discurso não é uma simples superfície de inscrição de objetos instaurados a priori, mas, sim, um conjunto de regras que constituem as condições de aparecimento histórico de tais objetos. Não é, tampouco, um simples fenômeno de expressão "de um sujeito que pensa, que conhece e que o diz: é, ao contrário, um conjunto em que podem ser determinadas a dispersão do sujeito e a sua descontinuidade em relação a si mesmo" (p. 61). Trata-se de

fazer a análise de um "regime de práticas" - as práticas sendo consideradas como o lugar de encadeamento do que se diz e do que se faz, das regras que se impõem e das razões que se dão, dos projetos e das evidências [ênfase adicionada].

Analisar "regimes de práticas" é analisar programações de conduta que têm, ao mesmo tempo, efeitos de prescrição em relação ao que se deve fazer (efeitos de "jurisdição") e efeitos de codificação em relação ao que se deve saber ("efeitos de veridicidade") [ênfase adicionada]. (Foucault, 2006, p. 338)

Entretanto, é fundamental destacar que esse tipo de análise não deve ser entendido no sentido de que se quer interrogar qual o valor de verdade dos textos investigados ou buscar o que por trás deles se oculta. O que se deseja é investigar como certas práticas sociais são aí significadas e produtoras de significações. Assumimos, dessa maneira, o documento como monumento, ou seja, como próprio objeto da história, não inócuo, não neutro, carregado de intenções e mediado por relações de poder. Permanecemos, assim, na dimensão do discurso, percorrendo a singular existência de enunciados que vêm à tona no que aí se diz e em nenhuma outra parte. E, uma vez que o discurso é conjunto de enunciados (Foucault, 2009), o que pretendemos operar é, na verdade, uma análise enunciativa:

uma análise histórica, mas que se mantém fora de qualquer interpretação: às coisas ditas, não pergunta o que escondem, o que nelas estava dito e o não-dito que involuntariamente recobrem, a abundância de pensamentos, imagens ou fantasmas que as habitam; mas, ao contrário, de que modo existem, o que significa para elas o fato de se terem manifestado, de terem deixado rastros e, talvez, de permanecerem para uma reutilização eventual: o que é para elas o fato de terem aparecido - e nenhuma outra em seu lugar [ênfase adicionada]. (p. 124)

Há que se dizer que o enunciado não consiste necessária e suficientemente em uma estrutura lógico-proposicional definida, tampouco em uma frase gramatical. Se algumas vezes o enunciado puder assumir e se ajustar a essas formas, é possível também acontecer que não lhes obedeçam. Por exemplo, ainda que "ninguém ouviu" e "é verdade que ninguém ouviu" não apresentem diferenças do ponto de vista lógico (equivalendo a uma mesma proposição), mas eles constituem enunciados distintos. Se forem a primeira linha de um romance, a primeira remeterá a uma constatação; a segunda só poderá constituir "um 
http://periodicos.sbu.unicamp.br/ojs/index.php/zetetike

monólogo interior, uma discussão muda, uma contestação consigo mesmo, ou um fragmento de diálogo, um conjunto de questões e de respostas" (Foucault, 2009, p. 91).

Por outro lado, a conjugação de um verbo disposta em colunas não pode ser considerada uma frase, mas constitui o enunciado das diferentes flexões pessoais de determinado tempo conjugativo verbal. Igualmente, não há frases, mas há enunciados, em um quadro classificatório de espécies botânicas, uma árvore genealógica, um livro contábil, uma equação ou fórmula algébrica.

Isto não implica, contudo, que, dado qualquer conjunto de signos ou de objetos apresentados à percepção, tenha-se um enunciado. O enunciado não é em si mesmo uma unidade, "mas sim uma função que cruza um domínio de estruturas e de unidades possíveis e que faz com que apareçam, com conteúdos concretos, no tempo e no espaço" (Foucault, 2009, p. 98). É por isso que o enunciado não é oculto nem visível, sendo necessária uma certa conversão do olhar e da atitude para que se possa reconhecê-lo e considerá-lo em si mesmo.

O enunciado não está ligado a um referente (tal como o está uma proposição), ou a um sentido (tal como o está uma frase), mas tão somente a um referencial. Ele não é constituído de "coisas", "fatos", "realidades", ou "seres", "mas de leis de possibilidade, de regras de existência para os objetos que aí se encontram nomeados, designados ou descritos, para as relações que aí se encontram afirmadas ou negadas" (p. 103).

O referencial do enunciado forma o lugar, a condição, o campo de emergência, a instância de diferenciação dos indivíduos ou dos objetos, dos estados de coisas e das relações postas em jogo pelo próprio enunciado; define as possibilidades de aparecimento e de delimitação do que dá à frase seu sentido, à proposição seu valor de verdade. É esse conjunto que caracteriza o nível enunciativo da formulação, por oposição a seu nível gramatical e a seu nível lógico: por meio da relação com esses diversos domínios de possibilidade, o enunciado faz de um sintagma, ou de uma série de símbolos, uma frase a que se pode, ou não, atribuir um sentido, uma proposição que pode ou não receber um valor de verdade (Foucault, 2009, p. 103).

Além disso, o sujeito de um enunciado não é nem o sujeito gramatical de uma frase, nem o indivíduo "real" que o articulou ou escreveu. O sujeito do enunciado é uma função vazia, podendo um único e mesmo indivíduo ocupar, alternadamente, variadas posições de sujeitos em uma série de enunciados diferentes. Um enunciado, ainda, nunca é geral ou livre, neutro e independente; está sempre fazendo parte de um conjunto, está sempre supondo outros enunciados adjacentes.

Por fim, o enunciado carrega uma materialidade, mais da ordem institucional do que espaço-temporal. É por isso que distintas enunciações podem comportar o mesmo enunciado (um discurso e sua tradução simultânea, ou as várias edições de um mesmo livro); e enunciações idênticas podem comportar diferentes enunciados (a enunciação de uma mesma frase não pode configurar o mesmo enunciado em Platão e em Freud). 
http://periodicos.sbu.unicamp.br/ojs/index.php/zetetike

\section{Desenhando}

De tudo isso, não pretendemos construir alguma espécie de história do referente, para a qual o desenho seria tomado como um objeto epistemológico. Mas, sim, uma história que trata esse saber como um objeto discursivo; que analisa o desenho como um conjunto de práticas significantes, inscrito em diversas tramas culturais, sendo produzido discursivamente e produzindo efeitos de verdade. Logo, não entendemos desenho como um corpo unificado e universal de conhecimentos, mas como um conjunto diverso de práticas de desenhar específicas, dentre as quais, algumas desejamos analisar.

Desprendemo-nos, pois, desse jogo de espelhos que insiste em fabricar uma imagem dual, e unitária, de agrupamentos que hoje nos são familiares, mas que, historicamente, veemse distribuídos e caracterizados de formas totalmente diferentes. Dessa forma, não partimos de um objeto dado, o desenho, como algo monossêmico e universal, buscando na história seu ponto de fundação e posteriormente seu desenvolvimento gradual. Isto remeteria a ver nas inscrições rupestres pré-históricas os rudimentos de um conhecimento (o desenho), ou de manifestações de usos comunicativos de imagens, que foi se aperfeiçoando ao longo do tempo. Embora tentador, isso carrega o grande perigo de projetar categorias sócio-históricas que são nossas em um tempo passado que apresentava outras características. Nem desenho existia como tal, tampouco comunicação visual era compreendida nos termos em que hoje se a entende.

O que procuramos, então, é "desrealizar" o desenho, fazendo a história de suas possibilidades, vasculhando suas camadas constitutivas, a fim de apreender o momento em que determinadas práticas de desenhar ganham consistência, dizibilidade e visibilidade. Saímos, assim, do terreno das origens e adentramos o campo de emergência de práticas de desenhar específicas. Nessa perspectiva - como objeto discursivo - o desenho não é unitário; é, ao contrário, dispersão de enunciados. É essa dispersão que queremos descrever, buscando o jogo das regras que tornou possível, durante determinado período, o aparecimento e a transformação de tais objeto(s).

Situamo-nos, desse modo, no nível do saber, que não é "nem o esboço enrugado, nem o subproduto cotidiano de uma ciência constituída", sequer "um canteiro epistemológico" (Foucault, 2009, p. 206). Que não é, tampouco, uma soma de conhecimentos (dos quais se pode dizer sempre se são verdadeiros ou falsos), mas um conjunto de elementos (objetos, tipos de formulações, conceitos e escolhas teóricas) formados regularmente no interior de uma prática discursiva.

Com isto, o que intentamos é fazer funcionar "instrumentos" foucaultianos específicos, em uma tentativa de aproximação a uma espécie de "arqueogenealogia" de determinadas práticas de desenhar (especificadas adiante). Mostrar, assim, como e por que uma "prática social-discursiva" "pode formar grupos de objetos, conjuntos de enunciações, jogos de conceitos, séries de escolhas teóricas" (p. 203). O que significa, "arqueologicamente", compreender as condições de possibilidade ou de emergência de um 
http://periodicos.sbu.unicamp.br/ojs/index.php/zetetike

determinado objeto, neste caso, certo tipo de desenho. Mas também, "genealogicamente", investigar sua transformação e seus usos em domínios diversos, perseguindo seus efeitos e as condições de sua disciplinarização.

Assim sendo, uma investigação dessa natureza está sempre no plural, exercendo-se em uma multiplicidade de registros, fazendo aparecer relações entre domínios discursivos e não discursivos. Ressaltemos, porém, não em uma análise simbólica ou causal, e sim, no sentido de compreender como e por que acontecimentos não discursivos fazem parte das condições de emergência, inserção e funcionamento de acontecimentos discursivos; de compreender como e por que esses acontecimentos estão inevitavelmente imbricados em um mesmo processo produtivo.

É com essas ferramentas teórico-metodológicas que adentramos o vasto território arqueológico em que práticas de desenhar podem ser investigadas. Vasto porque tais práticas desenrolam-se entre outras práticas e se articulam com elas, significadas em domínios de saber diversos, tais como o da anatomia, da botânica, da cartografia, da astronomia, da pintura, da arquitetura, da engenharia militar, dentre outros. Nesse sentido, em estudo preliminar (Machado \& Flores, 2013, pp. 255-279), já nos arriscamos pelos caminhos da anatomia e da pintura.

\section{Recortando}

Naquele momento, quando nos embrenhamos pelos caminhos da anatomia e da pintura, nosso enveredamento foi motivado pela percepção de que, no decorrer dos séculos XIX, o desenho do corpo humano tenha sido uma prática corrente nas Academias Militares e nas Academias de Belas Artes espalhadas pelo Brasil. Dória (2004, p. 16) afirma que, no âmbito militar, de finalidade eminentemente objetiva e prática, era ministrada uma diversidade de conteúdos tais como o desenho arquitetônico e de figuras, plantas e animais, também, o desenho de paisagem e as proporções do corpo humano [ênfase adicionada]. Nas Academias de Belas Artes, por sua vez, "o professor da Aula de Desenho deveria desenvolver nos seus alunos a habilidade da observação, o domínio das dimensões e proporções das formas e de noções de anatomia aplicada ao Desenho" [ênfase adicionada] (Trinchão, 2008, p. 140).

Também no século XX, a prática do desenho do corpo humano continuaria presente no ensino secundário brasileiro, ao menos nos discursos oficiais, inserida na modalidade do desenho do natural. A Portaria Ministerial s/n, de 30 de junho de 1931 (Ministério da Educação e Saúde Pública, 1931), que estabeleceu os programas do curso fundamental do ensino secundário, para a quarta série, determinava a cópia da figura humana, com representações parciais, feitas sumariamente em croquis de observação direta; e a figura humana em conjunto, com estudo de proporções. Para o curso complementar, a Portaria Ministerial s/n, de 17 de março de 1936 (Portaria BR, 1936) estabelecia para o Curso Médico, Farmacêutico e Odontológico, o estudo sintético do corpo humano, em diversas posições; 
http://periodicos.sbu.unicamp.br/ojs/index.php/zetetike

ligeiros esquemas anatômicos; partes do corpo humano; e desenho especializado de órgãos do corpo.

Uma década mais tarde, o desenho do corpo humano ficaria restrito ao curso científico ${ }^{7}$. A Portaria Ministerial n. 10, de 04 de janeiro de 1946 (Portaria BR, 1946) estabelecia, para a segunda série, a representação da figura humana com estudo das proporções do corpo humano; estudo elementar das proporções do corpo humano apresentado de frente, de costas e de perfil; e representação em esboço, das devidas proporções, de várias proporções do corpo humano. Já para a terceira série, determinava a representação de partes da figura humana, como elementos da osteologia, tais quais, o fêmur, a tíbia, o perônio, o maxilar inferior, etc., e a representação do esqueleto da cabeça; ainda, a representação de órgãos do corpo humano, como a representação esquemática de cortes do coração, do aparelho visual e do aparelho auditivo, com as respectivas indicações morfológicas de seus pormenores.

Desse estudo (Machado \& Flores, 2013), percebemos a evidente diferença de significações atribuídas à prática do desenho do corpo na atividade artística e na atividade médica. Nesta, os desenhos nas pranchas anatômicas deveriam servir como uma espécie de recurso didático, concebidos como mapas do corpo. Naquela, a ideia era preencher de forma mais natural e realista um determinado espaço em uma pintura. Não obstante, os usos do desenho do corpo a partir dessas atividades transgrediram suas fronteiras, provocando implicações filosóficas, conceituais, técnicas e também científicas.

$\mathrm{Na}$ verdade, uma cultura visual lentamente iniciava-se em função do "descobrimento de técnicas de ilustração desenvolvidas nos ateliês dos artistas renascentistas e à intensa atividade editorial da época, que lentamente descobria o "poder da ilustração"" (Kickhofel, 2003, p. 397). Donde argumentamos que o desenho, a partir do Renascimento, começou a experimentar novos papéis, na transição de uma cultura de memória e instrução para uma cultura de descoberta e invenção. Se antes uma de suas funções era servir como um recurso facilitador na compreensão de determinado assunto por parte dos não letrados, daqueles incapazes de apreender o discurso escrito, agora, aos poucos, passava a adquirir poder explicativo equiparável ao das palavras, ao possibilitar descrever com maior exatidão as observações advindas da experiência.

O desenho, portanto, fez-se suporte de um ideário descritivo das coisas do mundo, instaurado a partir do Renascimento. Ao viabilizar essas novas necessidades, principalmente pela descrição racional do espaço pela técnica da perspectiva geométrica e da descrição naturalista do corpo humano por meio da observação anatômica, gradativamente informou e foi informado por conhecimentos científicos, em especial matemáticos. Foi uma nova

\footnotetext{
${ }^{7}$ Entre 1942 e 1946, foram decretadas as Leis Orgânicas de Ensino, que ficaram conhecidas por Reforma Capanema. Essa reforma, consolidada em seis decretos-leis, organizou o ensino primário, secundário, bem como o ensino industrial, comercial, normal e agrícola. O ensino secundário continuou dividido em dois ciclos, mas ganhou uma configuração diferente: o $1^{\circ}$ ciclo, ou curso ginasial, teve a duração alterada de cinco para quatro anos e o $2^{\circ}$ ciclo, ou curso colegial, de dois para três anos, sendo que esse foi subdividido em duas modalidades distintas, o clássico e o científico.
} 
http://periodicos.sbu.unicamp.br/ojs/index.php/zetetike

roupagem que lhe coube a partir daí, possibilitando-lhe adentrar atividades que não somente a artística. E assim, para além das descrições anatômicas, práticas de desenhar também foram sendo incorporadas nas descrições botânicas, na cartografia, na engenharia militar, nas geometrias projetiva e descritiva, nos projetos técnicos da revolução industrial, dentre tantos outros. Daí que, oriundas desses variados campos de saber, diversas práticas de desenhar tornaram-se disciplinarizadas a partir do século XVIII, inseridas na atividade escolar.

Pois bem. Voltemos agora à problematização central que movimenta nossa investigação: como práticas sociais de desenhar teriam adquirido o estatuto de conteúdo escolar? Destacamos que essa incursão inicial pelos caminhos da pintura e da anatomia, bem como as diversas leituras empreendidas, nos indicou ser mais produtivo para a análise que se propõe limitar o campo de pesquisa às práticas cartográficas, deixando as demais pretendidas para pesquisas futuras. Esta escolha não se dá, então, por motivações pessoais/subjetivas (já que, de fato, quaisquer outras práticas de desenhar poderiam igualmente ter sido escolhidas), mas porque o que dizemos "não é dito de qualquer lugar. É considerado, necessariamente, no jogo de uma exterioridade" (Foucault, 2009, p. 139); não em uma síntese ou função unificante que supostamente exerceríamos, mas, ao contrário, à manifestação neste texto de nossa própria dispersão: nos diversos status, lugares e posições que ocupamos, na descontinuidade dos planos de onde falamos, na especificidade de uma prática discursiva (p. 61).

Assim, se escolhemos a cartografia como campo de análise é pelo fato de percebermos que neste domínio as ligações entre desenho e sua disciplinarização são densas e numerosas. E porque vemos aí um emaranhado de interpositividades cujos limites e pontos de cruzamentos são bastante porosos. A cartografia apresenta-se, dessa forma, não como um território de fronteiras fixadas, sob um efeito unificador, mas, sim, como um potente multiplicador, que permite o trânsito por uma variedade daqueles outros domínios, tais como o da geografia, da astronomia, da arquitetura, da engenharia militar, da arte e da matemática.

Isto porque sugerimos que, assim como em relação à matemática ${ }^{8}$, estão nas Academias Militares e na "arte da guerra" as origens do desenho como disciplina escolar, especialmente a partir do século $\mathrm{XVI}^{9}$. Das necessidades de defesa emergentes em fins do século XV, e estendidas ao longo dos séculos seguintes, os tratados sobre fortificação foram multiplicados, a formação do engenheiro militar "aclamada", e "a geometria e o desenho passaram assim, a constituir uma forma privilegiada de transmissão de conhecimentos e de representação das coisas, além de um meio didático de reconhecido alcance prático" (Soromenho, 2001, p. 22). Estes tratados militares surgidos da "arte da fortificação" nos séculos XVI e XVII foram um propulsor do que mais tarde seria o desenho como disciplina

\footnotetext{
${ }^{8}$ Esta compreensão quanto à Matemática é defendida, por exemplo, por autores tais como o historiador francês Bruno Belhoste e, especificamente no Brasil, por Valente (2007), que apontam uma estreita ligação entre guerra e educação matemática, no sentido de que as matemáticas escolares têm nas Academias Militares suas origens.

${ }^{9}$ Toda a argumentação relativa a esta questão, que desenvolvemos a seguir, é oriunda da pesquisa desenvolvida por Machado (2012), também publicada em forma de livro (Machado \& Flores, 2013b).
}

Zetetiké, Campinas, SP, v.24, n.2, maio/ago.2016, p.237-248

ISSN 2176-1744 
http://periodicos.sbu.unicamp.br/ojs/index.php/zetetike

escolar, sistematicamente organizada. Segundo Trinchão (2008), o desenho, tomado como objeto de ensino, tem suas origens nos tratados de artistas, artesãos e principalmente, nos manuscritos de professores de escolas militares:

essa produção iniciou no século XVI e se expandiu no século XVIII. O ensino de desenho luso-brasileiro era ministrado baseado em cópias manuscritas, ou impressas, de tratados estrangeiros e em materiais didáticos organizados e manuscritos criados pelos próprios professores, cujos fundamentos foram absorvidos de tratados italianos, espanhóis e franceses. (p. 237)

A competência em construção de fortificações foi um elemento fundamental da formação militar instituída, e a essa competência o saber em desenho esteve inextricavelmente entrelaçado, ganhando visibilidade e importância. Por isso é que a cartografia configura-se em um (dentre tantos) rico território de análise, já que a elaboração e o conhecimento de mapas para as construções arquitetônicas a serem empreendidas e para as análises dos locais a serem atingidos belicamente eram fortemente requeridos. Utilizamo-nos dela [a cartografia], portanto, estrategicamente como "ponto de ataque" para buscar o feixe de problematizações que deu as condições de possibilidade para a emergência do desenho.

\section{Arrematando}

Disto, pensamos que fica justificado o recorte de pesquisa que operamos, limitando nossa análise, em especial, ao território da cartografia. Tratamos, doravante, de buscar o "como" e o "porque" histórico-cultural de práticas de desenhar (especialmente aquelas imbricadas neste domínio), analisando alguns dos dispositivos de enunciação constitutivos de um campo disciplinar e profissional que foi sendo escolarizado ao longo, principalmente, do século XVIII. Ressaltamos ainda que, estrategicamente, tomamos um estrato temporal específico para a análise que propomos: aquele designado por Foucault (2007) como Época Clássica - período que se estende do Renascimento até a época da Revolução Francesa (1789). Destacamos, outrossim, que com isso se designa menos um período histórico e mais um "modo de ser das coisas e da ordem" (p. XIX). Acreditamos que é justamente a alteração na forma geral do saber que se opera nesse período, a que alude Foucault, a condição de possibilidade para que determinadas práticas de desenhar se tornassem socialmente valorizadas e disciplinarizadas.

Por fim, evidenciamos que é consciente de nossa não pertença a um campo disciplinar específico, que nos permitisse assumir a posição de historiadoras, que nos arriscamos tão somente a tecer história(s). O que significa que este é, portanto, um estudo de história, mas não um trabalho de historiador (Foucault, 1984, p. 13). Tentamos apenas gozar de certa liberdade de escrita para produzir narrativas a partir de peregrinações a terras por vezes desconhecidas e distantes, dentre as quais, as terras historiográficas. Procuramos, então, ao produzir essas narrativas, atuar como ensaístas, "como um leitor que escreve e um escritor que lê" (Larrosa, 2003, p. 107); seguindo o caminho sinuoso que se adapta aos acidentes do terreno e não o caminho retilíneo daquele que sabe previamente aonde vai (p. 111). 
http://periodicos.sbu.unicamp.br/ojs/index.php/zetetike

\section{Referências}

Chervel, A. (1990). História das disciplinas escolares: reflexões sobre um campo de pesquisa (G. L. Louro, trad.). Teoria e Educação, 2, 177-229.

Chevallard, Y. (2009). La transposición didáctica (3a ed.). Buenos Aires: Aique Grupo Editor.

Deleuze, G. Foucault. (2005). São Paulo: Brasiliense.

Dória, R. P. (2004). Entre o belo e o útil: manuais e práticas do ensino do desenho no Brasil do século XIX. 237f. Tese de Doutorado em Estruturas Ambientais Urbanas, Universidade de São Paulo, São Paulo.

Foucault, M. (1984). História da sexualidade II: o uso dos prazeres. Rio de Janeiro: Graal.

Foucault, M. (2006). Ditos e escritos IV. Estratégia, Poder-Saber (2a ed., M. B. da Motta, org., Ribeiro, V. L. A., trad.). Rio de Janeiro: Forense Universitária.

Foucault, M. (2007). As palavras e as coisas (9a ed.). São Paulo: Martins Fontes.

Foucault, M. (2009). A arqueologia do saber (7a ed.). Rio de Janeiro: Forense Universitária.

Foucault, M. (2013). A verdade e as formas jurídicas. Rio de Janeiro: Nau.

Hall, S. (1997, julho/dezembro). A centralidade da cultura: notas sobre as revoluções culturais do nosso tempo. Educação \& Realidade, 22(2), 15-46.

Kickhofel, E. H. P. (2003). A lição de anatomia de Andreas Vesalius e a ciência moderna. Scientia \& Studia, 1(3), 389-404.

Larrosa, J. (2003). O ensaio e a escrita acadêmica. Educação \& Realidade, 28(2), 101-115.

Lecourt, D. (2008). A Arqueologia e o saber. In S. P. Rouanet, \& J. G. Merquior (Orgs.), $O$ homem e o discurso. A arqueologia de Michel Foucault (2a ed., pp. 43-66). Rio de Janeiro: Tempo Brasileiro.

Machado, R. B. (2012). Entre vida e morte: cenas de um ensino de desenho. 254f. Dissertação de Mestrado em Educação Científica e Tecnológica, Universidade Federal de Santa Catarina, Florianópolis.

Machado, R. B.; Flores, C. R. (2013a). O corpo despido pelas práticas de desenhar: dos usos à disciplinarização do desenho. BOLEMA, 27(45), 255-279.

Machado, R. B; Flores, C. R. (2013b). Cenas de um ensino de desenho. São Paulo: Editora Livraria da Física. (Coleção história da Matemática para professores).

Miguel, A. (2010, abril). Percursos indisciplinares na atividade de pesquisa em História (da Educação Matemática): entre jogos discursivos como práticas e práticas como jogos discursivos. BOLEMA, 23(35A), 1-57.

Miguel, A. (2014). Is the mathematics education a problem for the school or is the school a problem for the mathematics education? RIPEM, 4(2), 5-35.

Soromenho, M. (2001). Descrever, registrar, instruir: práticas e usos do desenho. A ciência do desenho: a ilustração na colecção de códigos da Biblioteca Nacional. Lisboa: Ministério da Cultura, Biblioteca Nacional. 
http://periodicos.sbu.unicamp.br/ojs/index.php/zetetike

Trinchão, G. M. C. (2008). O desenho como objeto de ensino: história de uma disciplina a partir dos livros didáticos luso-brasileiros oitocentistas. $496 \mathrm{f}$. Tese de Doutorado em Educação, Universidade do Vale do Rio Sinos, São Leopoldo, RS, Brasil.

Valente, W. R. (2007). Uma história da matemática escolar no Brasil: 1730-1930 (2a ed.). São Paulo: Annablume.

Legislação

Ministério da Educação e Saúde Pública (1931). Portaria Ministerial s/n de 30 de junho de 1931. Dispõe sobre os programas do curso fundamental do ensino secundário e instruções metodológicas - Desenho. Diário Oficial da União. Rio de Janeiro, ano LXX, n. 178, 30 jul. 1931. pp. 12.423-24.

Portaria Ministerial s/n, de 17 de março de 1936. (1936). Dispõe sobre os programas do curso complementar - Desenho. Diário Oficial da União. Rio de Janeiro, ano LXXV, n. 66, 19 mar. 1936. pp. 5.824-5.825.

Portaria Ministerial n.10, de 04 de janeiro de 1946. (1946). Expede programas de Desenho e respectivas instruções metodológicas e determina sua execução nos cursos colegial e científico do ensino secundário. Diário Oficial da União. Rio de Janeiro, ano LXXXV, n. 11, 14 jan. 1946. pp. 609-611.

Submetido em: 23/12/2016

Aceito em: 11/07/2016 